
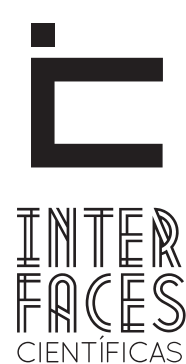

HUMANAS E SOCIAIS

ISSN IMPRESSO 2316-3348

E-ISSN 2316-3801

DOI - 10.17564/2316-3801.2018v7n1p83-94

\title{
PRECONCEITO VELADO: A NOVA FORMA DE ESTEREOTIPAR A MULHER
}

\author{
VEELED PREJUDICE: A NEW FORM OF WOMEN STEREOTYPING \\ PREJUICIO SUTIL: UNA NUEVA FORMA DE ESTEREOTIPAR MUJERES
}

Claudia Rosa Acevedo ${ }^{1}$

Caroline Westphal ${ }^{3}$
Bruno Catão ${ }^{2}$

Helenita Tamashiro ${ }^{4}$

\section{RESUMO}

O objetivo deste trabalho é compreender como a mulher é representada em tirinhas. Nós utilizamos como abordagem metodológica a análise de conteúdo qualitativa. Os resultados revelam que, majoritariamente, a mulher é representada de forma negativa. Mesmo quando ela é descrita de forma positiva, tal imagem é caricaturada com traços pejorativos, denunciando um novo tipo de preconceito, que é consubstanciado de forma velada.

\section{PALAVRAS-CHAVE}

Gênero. Estereótipo. Histórias em Quadrinhos. Mídia de Massa. Tirinhas. 


\section{ABSTRACT}

The objective of this paper is to understand how women are represented in strips. We applied the qualitative content analysis approach to understand our data. The results show that women are representedin a negative way. Even when it is described positively this image is caricatured with derogatory traits, de-

\section{RESÚMEN}

El objetivo de este trabajo es entender cómo se representan las mujeres en tiras de cómics a través del análisis de contenido cualitativo. Los resultados muestran que, mayoritariamente, las mujeres son representadas negativamente. Incluso cuando las imágenes se describen de manera positiva, que se presentan con características peyorativas, de- nouncing a new kind of prejudice, which is embodied in a veiled way.

\section{KEYWORDS}

Gender. Stereotyping. Comics. Mass media. Comic Strips nunciando un nuevo tipo de prejuicio, que se materializa en forma sutil.

\section{PALAVRAS CLAVE}

Género. Estereotipo. Cómics. medios de comunicación . Tiras. 


\section{INTRODUCÇÃO}

Este estudo usa tirinhas humorísticas para entender como se dá a estereotipização feminina nesta mídia (LAVIN, 1998; MORAES, 2008). A temática da representação feminina em tirinhas já foi estudada por Lavin (1998), mas aqui pretende-se fazer um estudo de caso mais específico, focando em três tiras seriadas de alta circulação.

Quadrinhos são consumidos majoritariamente pelo público entre 13 e 18 anos (CAIXETA, 2015), fazendo com que seja uma mídia importante na formação cognitiva de seus consumidores e que vem crescendo em alcance nas últimas décadas graças ao cinema.

O preconceito e os estereótipos são ferramentas comuns no humor das tiras seriadas (CAIXETA, 2015). Mazzara (1999) define estereótipos como formas de economia cognitiva por meio das quais o mundo e o outro são classificados em categorias rígidas que facilitam a generalização. 0 humor pode se dar com a inversão do estereótipo - que não é a sua negação, mas confirma sua existência na mente do público e do autor.

\section{MATERIAL E MÉTODOS}

Tiras são um subgênero dos quadrinhos, uma mídia que utiliza imagens sequenciadas para contar uma história (EISNER, 1989). O humor da tira cômica seriada é alcançado usando elementos como o desfecho inesperado da narrativa.

Este trabalho envolveu dois tipos de pesquisa: exploratória (MATTAR, 1994) e análise de conteúdo qualitativa segundo Bardin (1977).

A etapa exploratória teve como objetivo o levantamento bibliográfico de teses, dissertações, artigos, livros, publicações e pesquisas (ACEVEDO,1998) para compreender as formas como ocorre a representação da mulher no gênero literário das tirinhas.

Em seguida, utilizou-se a técnica da análise de conteúdo (BARDIN, 1977), que é uma técnica de análise que usa descrições exaustivas dos elementos textuais, explícitos e implícitos, com o objetivo de enri- quecimento da leitura e descoberta de elementos que levem a uma interpretação completa.

Séries utilizadas:

Mafalda: criada nos anos 1960 pelo cartunista argentino Quino, a série de tirinhas de jornal segue a vida da personagem título, uma criança de cerca de 6 anos que regularmente mostra uma lógica muito além de sua idade ao criticar atitudes adultas.

Aline: fruto do trabalho do cartunista Adão Iturrusgarai nos anos 1990; Aline trata da vida de uma jovem que mora com seus dois namorados. 0 humor usa bastante de choque moral e inversão de estereótipos.

Mulher de 30: Esta tira era muito popular nas redes sociais à época em que o trabalho foi desenvolvido. Nela, as protagonistas se alternam, recriando situações da vida de mulheres na faixa dos 30 anos.

Para a análise, foram selecionadas 3 tiras dos dois primeiros anos de suas publicações. As fontes utilizadas foram "Aline: Era uma vez..." - livro publicado pela editora Devir em 2001, "Mafalda Inédita" -, este publicado pela editora Martins Fontes em 1993, e o site http://mulher30.com.br.

Após a seleção das tiras, fizemos a análise de forma interpretativa, desconstruindo nelas os discursos sobre a mulher para identificar como ocorre sua representação de acordo com o que nosso levantamento bibliográfico preliminar apontou. Além disso, analisamos os componentes verbais e não verbais nas histórias, seguindo a técnica descrita por Bardin (1977).

Por meio da pesquisa exploratória realizada nos trabalhos de Goffman (1978), Kang (1997), Acevedo (2005), Venkatesan e Losco (1975), Belkaoui e Belkaoui (1976), Courtney e Lockeretz (1971), Jaffe e Berger (1994) foram adotadas nove categorias de análise, as quais são descritas a seguir:

Postura submissa (GOFFMAN, 1978; KANG, 1997): A mulher representada nesta categoria aparece em posições inferiores, expressando subordinação ou comportamento submisso. Esta atividade poderia acontecer tanto em um ambiente organizacional ou fora dele. Posturas curvadas podem ser entendidas como a aceitação da subordinação e expressão de obediência. 
Definição Operacional: Homem ensinando a mulher; mulher servindo o homem; homem em uma posição hierárquica superior em relação à mulher; o homem determina o que deve ser feito; abaixando-se fisicamente; ajoelhando-se; corpo ou cabeça curvados para baixo; deitado ou sentando na cama ou no chão.

Independência (KANG, 1997; ACEVEDO et al., 2005): A mulher é representada como sendo financeiramente ou psicologicamente independente dos homens.

Definição Operacional: A mulher é financeiramente independente do homem. Ela possui um trabalho e se sustenta sozinha. A mulher é psicologicamente independente do homem. Ela completa tarefas sozinhas; não precisa de encorajamento ou reforço masculino; toma decisões e iniciativas sozinha. Não precisa do homem para cuidar dela.

Dona de casa (VENKATESAN; LOSCO, 1975; BELKAOUI, 1976; ACEVEDO et al., 2004): Nesse papel, a mulher é apresentada como dona de casa em tempo integral e não possui nenhum tipo de atividade profissional. Cuidar da casa e da família é a atividade central de sua vida.

Definição operacional: Mulher preocupada ou engajada em atividades da casa ou preocupada com a limpeza. Mulher preocupada em ser uma boa esposa. Dependentes do homem (COURTNEY; LOCKERETZ, 1971; VENKATESAN; LOSCO, 1975): São colocadas como dependentes financeiramente ou psicologicamente dos homens.

Definição Operacional: Financeiramente dependente: ela não se mostra capaz de se sustentar sozinha. Não possui salário ou trabalho. Depende do homem para viver. Psicologicamente dependente: para completar tarefas ela precisa de instruções de um homem, de reforço masculino; não toma decisões sozinha; não toma a iniciativa; precisa de um homem para tomar conta dela.

Objeto sexual (KANG, 1997; ACEVEDO et al., 2005): Quando a mulher é retratada, mostrando um alto grau de nudez, com roupas que exibem o corpo ou completamente nua.

Definição Operacional: Modelos femininas, vestindo roupas que exibem o corpo (minissaias, saias apertadas, shorts, roupas transparentes, roupa de banho) ou nudez (usando roupas íntimas, enroladas em toalhas, nuas).

Fisicamente bonita (VENKATESAN; LOSCO, 1975; ACEVEDO et al., 2005): Mulheres cujo foco principal na vida é tornar-se mais bonita. Esse papel é relacionado com a imposição de uma certa imagem, que é sempre magra, bonita e jovem.

Definição operacional: Mulher preocupada com produtos cosméticos, ou acessórios extravagantes que destacam a beleza física. Preocupada em parecer mais jovem, magra e atraente.

“Boa-vida” (VENKATESAN; LOSCO, 1975): Definição teórica e operacional coincidem: A mulher é preocupada com atividades e assuntos superficiais. Seu foco principal é gastar dinheiro, divertir-se, comprar e consumir produtos caros para participar de atividades luxuosas.

Papéis decorativos (BELKAOUI; BELKAOUI, 1976; VENKATESAN; LOSCO, 1975): Quando há uma mulher em um anúncio, mas sem estabelecer alguma relação com o produto. Ela apenas tem um papel decorativo.

Definição operacional: A mulher não possui relação com a ação principal. Apesar de estar no primeiro plano da cena, não exerce nenhuma função. Ela é trazida no final da cena, ou é mostrada muito rapidamente. Além disso, ela está no plano de fundo da cena.

Super-mulher (JAFFE; BERGER, 1994; ACEVEDO et al., 2005): Definição: Nesta imagem a mulher gerencia os problemas do trabalho, família e casa. Apesar de ter um trabalho, ela não divide as tarefas de casa e da família com o marido. Refere-se a mulheres em posições de prestígio, recebendo um salário alto ou com uma boa e refinada educação. Exemplos são: juízas, professoras de faculdade, executivas, doutoras.

Definição operacional: A mulher atua em diversos papéis ao mesmo tempo; ela é esposa, mãe e dona de casa. Entretanto, ela toma conta da casa e da família sozinha. Ela não divide essas atividades com o marido.

Ambos os livros com as coletâneas de tirinhas utilizadas podem ser encontrados gratuitamente no acervo da Gibiteca Henfil, da biblioteca do Centro Cultural de São Paulo, próximo à estação Vergueiro do Metrô. A webtira pode ser encontra em http://mulher30.com.br. 


\section{ANÁLISE DAS TIRAS}

Figura 1 - Tira de “Mafalda”, 10 de novembro de 64
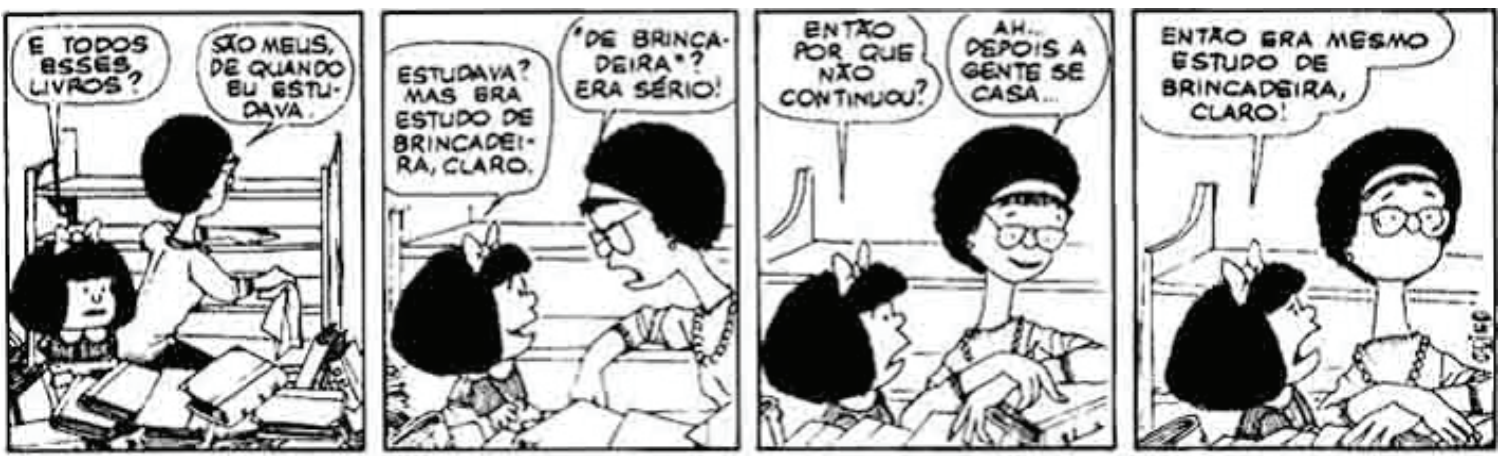

Fonte: Mafalda inédita. São Paulo: Martins Fontes, 1993

A tira de 10 de novembro de 1964 tem como personagens Mafalda e sua mãe, Raquel. Mafalda é uma criança argentina de 6 anos com traços de criança prodígio e visão crítica que costuma faltar a adultos. A comicidade da tira se dá pelo diálogo entre mãe e filha e pela expressão da mãe ao final.

A cena parece se desenrolar no ambiente familiar, uma conversa entre Mafalda e a mãe, que limpa uma estante empoeirada cheia dos livros que utilizara na faculdade. 0 cômico aparece pela crítica expressa à sociedade pelos olhos da personagem Mafalda. 0 juízo refere-se ao fato de muitas mulheres terem cursado ensino superior e depois terem abandonado seu diploma e escolhido se dedicarem ao papel de "dona de casa” (VENKATESAN; LOSCO, 1975; BELKAOUI, 1976; ACEVEDO et al., 2004), enquanto o seu cônjuge masculino trabalha para prover a família. 0 absurdo dessa realidade fica proferido na conclusão da menina: "então era mesmo estudo de brincadeira, claro!"

Figura 2 - Tira de “Mafalda”, 12 de dezembro de 1965
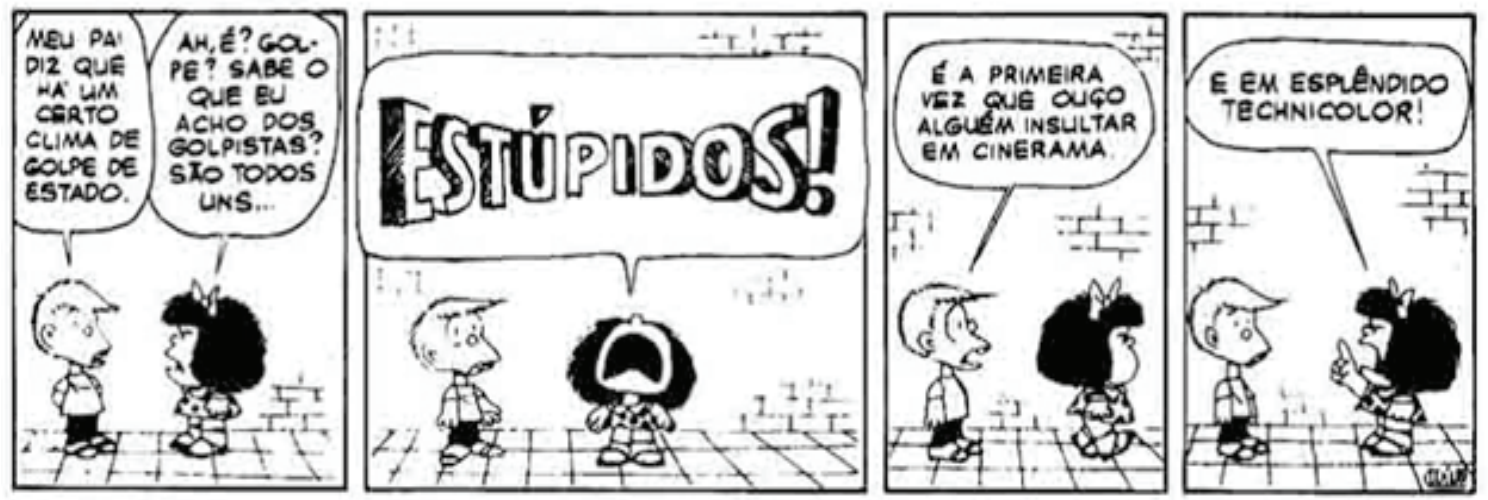

Fonte: Mafalda inédita. São Paulo: Martins Fontes, 1993

A cena se desenrola num ambiente genérico, provavelmente numa rua qualquer de bairro qualquer. Os per- sonagens envolvidos são Mafalda e seu amigo Filipe. Na tira de 12 de dezembro de 1965, o humor é concretizado 
pelo nonsense da metalinguística que aparece quando Filipe comenta a fala de Mafalda, que segundo ele estaria em "cinerama" (formato de letra comum ao cinema), e, Mafalda acrescenta: em "esplêndido technicolor" (técnica de dar cor aos filmes muito utilizada nos antigos de- senhos animados da Disney e do Pica-Pau, por exemplo). Mafalda refere-se a um assunto político polêmico, sendo este a iminência do golpe militar que já se instaurara na Argentina, revelando-se assim uma personagem detentora do estigma "criança prodígio".

Figura 3 - Tira de “Mafalda”, 3 de outubro de 1972
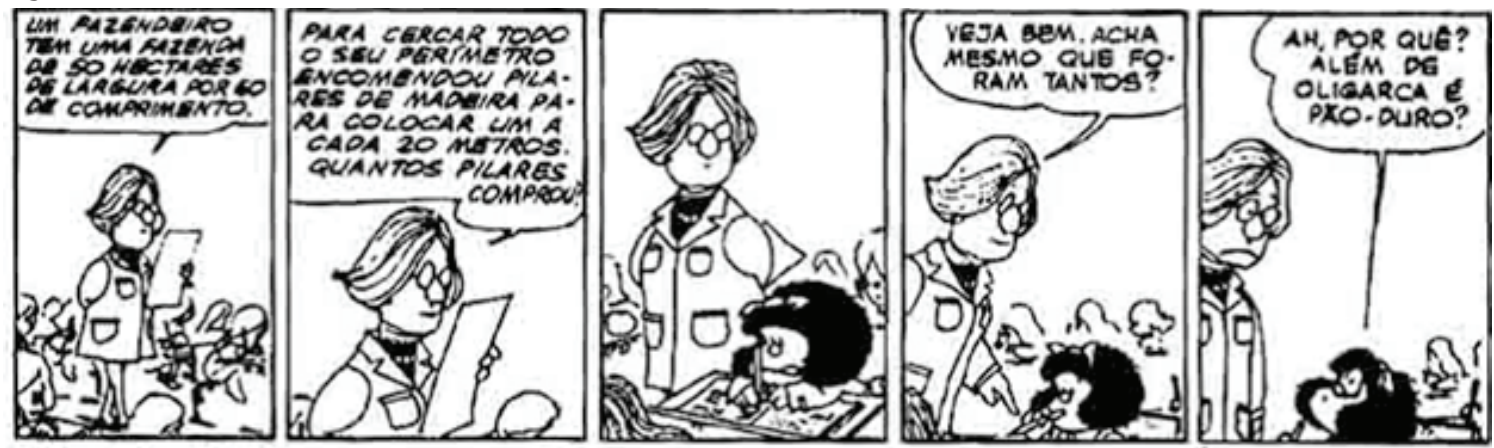

Fonte: Mafalda inédita. São Paulo: Martins Fontes, 1993

A última tira de Mafalda sobre a qual falaremos se desenrola no ambiente escolar, o diálogo, acontecendo entre Mafalda e sua professora. Na tira de 3 de outubro de 1972, temos como personagens Mafalda e uma professora de matemática. Apesar da mulher não se encontrar em casa, lavando pratos ou tirando o pó dos móveis, ela ainda se encontra ligada à educação infantil, profissão estigmatizada como inerentemente feminina. Basicamente, cuidando dos filhos dos ou- tros e, encaixando-se, deste modo, na categoria de "dona de casa" (VENKATESAN; LOSCO, 1975; BELKAOUI, 1976; ACEVEDO et al., 2004).

Nas tiras da série Aline, o autor Adão Iturrusgarai retrata sua concepção dos jovens urbanos, modernos e "abertos", principalmente no tocante a seus relacionamentos sexuais. Além disso, discute questões polêmicas como a poligamia, o uso de drogas, entorpecentes e gravidez na adolescência (BARCELLOS, 1999).

Figura 4 - Uma das primeiras tiras de "Aline"
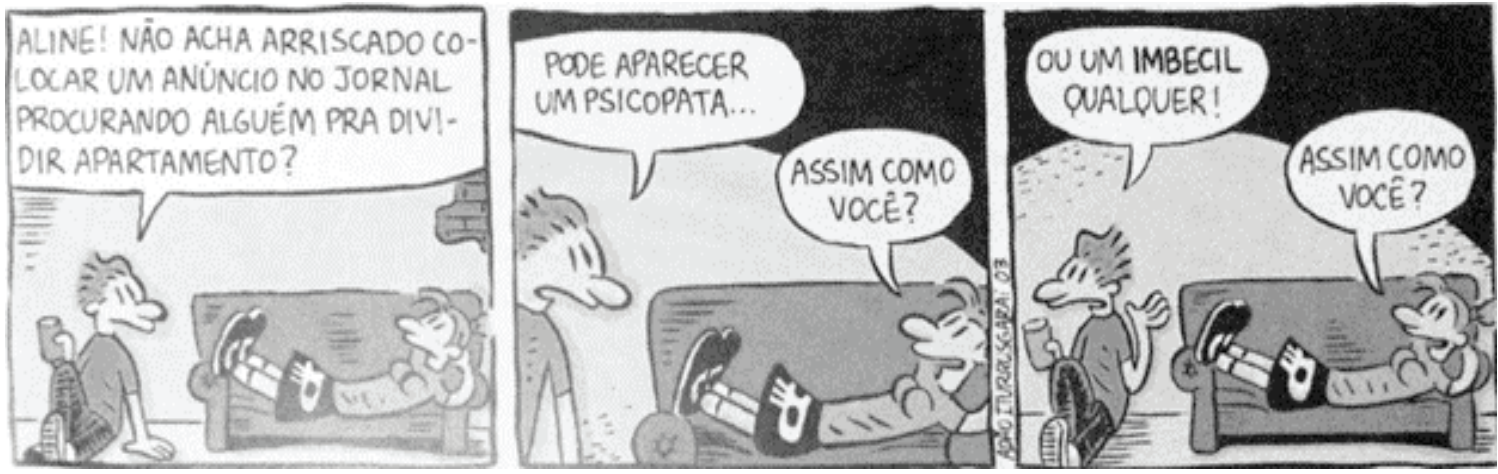

Fonte: Aline: era uma vez... São Paulo: Devir, 2001. 
A situação mostrada na tira se desenrola no apartamento que Aline divide com seu companheiro. A atitude dos dois, um sentado no chão com uma latinha de cerveja ou refrigerante, a outra deitada no sofá, pernas para o alto, ainda de sapatos, mostra algo como relaxamento, ou até um certo desleixo, o que é evidenciado pela parte da parede com tijolos expostos. Examinando as narrativas de Aline, podemos identificar uma mulher corajosa, despreocupada e ao mesmo tempo conformada, que aceita as características reprováveis de seu companheiro sem imposições ou questionamentos.

Aline não se dá ao trabalho de levar adiante a discussão, mostrando indiferença. Isto, acompanhado pelo fato de que ela ocupa todo o sofá enquanto o namorado senta no chão, revela que a moça tem certo controle e poder de veto sobre a relação. Não vê neces- sidade de contra argumentar o parceiro e está numa posição confortável de quem acredita que tomará a decisão final independentemente da opinião do outro. Tal situação induz à essa personagem a categoria "independente" (KANG, 1997; ACEVEDO et al., 2005).

O homem inseguro, receoso, colocado em uma posição mais baixa que a mulher (ele no chão e ela no sofá), querendo discutir algo que o está incomodando contrapõe-se à mulher segura, despreocupada, em posição levemente superior na imagem que finaliza a tentativa de diálogo iniciada pelo homem. Esta contraposição traz a sensação de inversão dos papéis comumente cultivados na sociedade em que o homem seria expresso como superior (GOFFMAN, 1978; KANG, 1997), estável e seguro, que não gosta de dialogar.

Figura 5 - Tira de "Aline”, já com os dois namorados
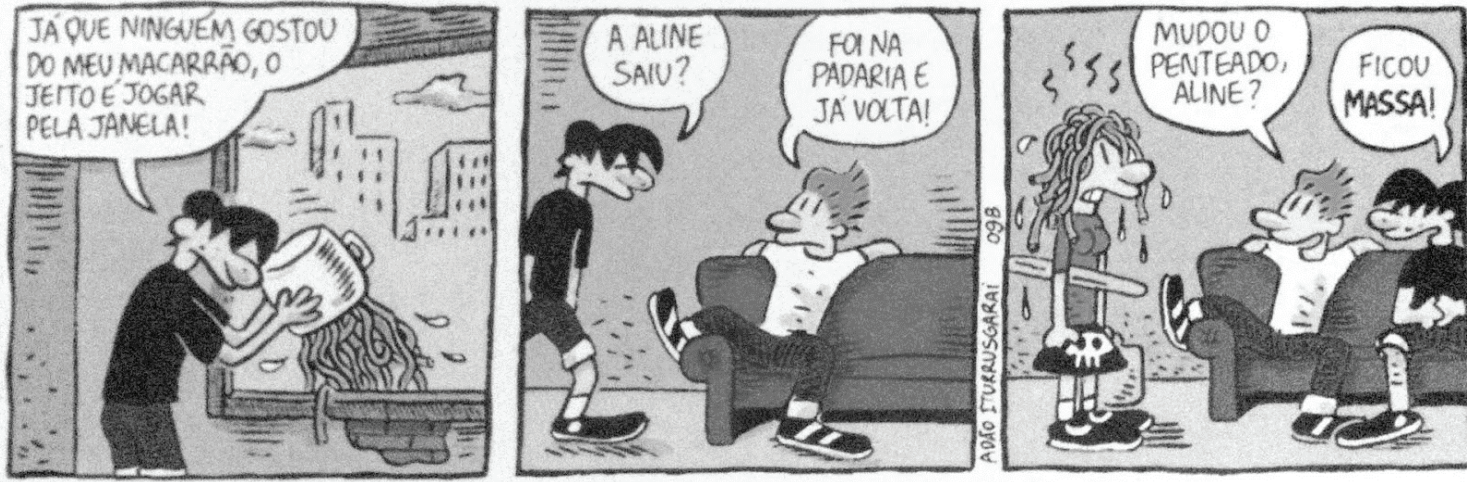

Fonte: Aline: era uma vez... São Paulo: Devir, 2001.

A segunda tira analisada já traz o trio de protagonistas formado, o novo parceiro de Aline já ocupando seu lugar no apartamento dos jovens. Um deles cuida das tarefas da casa, enquanto o outro se espalha no sofá, e Aline está fora de casa. O segundo quadro da tira traz a mulher que foi à padaria, enquanto os dois homens ficaram em casa sentados no sofá. Observa-se a inversão dos papéis. Os homens encontram-se na função de "dona-de-casa” (VENKATESAN; LOSCO, 1975; BELKAOUI; BELKAOUI, 1976; ACEVEDO et al., 2004) e "boa-vida" (VENKATESAN; LOSCO, 1975), o que se evidencia tanto pelo fato de um deles cozinhar, quanto pela postura relaxada do outro, no sofá. Além disso, remete-se à categoria de "super-mulher", já mencionada por Jaffe e Berger (1994), Acevedo e outros autores (2004). 
Figura 6 - Tira de "Aline"em que a protagonista escreve para o pai sobre os namorados
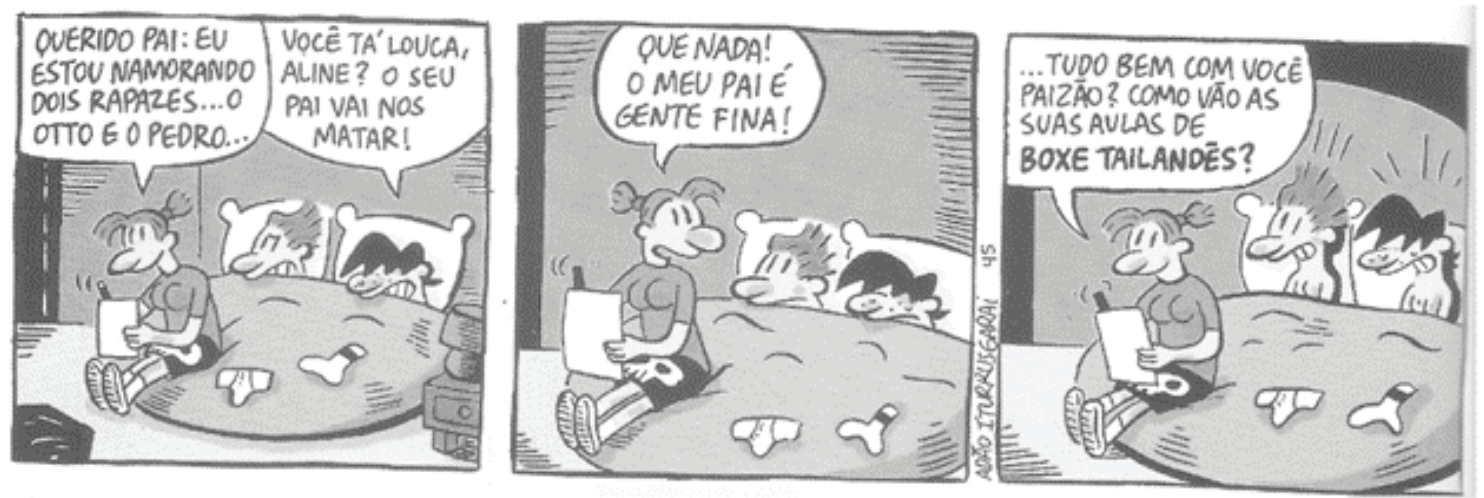

Fonte: Aline: era uma vez... São Paulo: Devir, 2001.

A última tira de Aline analisada neste trabalho se dá no quarto dos jovens. Aline escreve uma carta para seu pai, enquanto seus dois namorados, Otto e Pedro, estão deitados, presumivelmente nus sob as cobertas. Na tira acima está presente a ideia de uma hierarquia masculina que gira em torno da mulher. Primeiro a mulher deve satisfações a seu pai, seu tutor, até que ela passe a se submeter a outro homem, geralmente seu marido, ou no caso de Aline, seus dois namorados. Esta hierarquia de poder sobre a mulher reflete-se na categoria feminina que Goffman (1978) e Kang (1997) descrevem como "postura submissa”, na qual é o homem quem decide o que deve ser feito. Fica claro que a vida amorosa e sexual de Aline deve passar pelo veto do pai, sob uma ameaça física vinda do fato de que o pai de Aline é professor de boxe tailandês.

Figura 7 - Tira de "Mulher de 30" com a personagem Sabrina
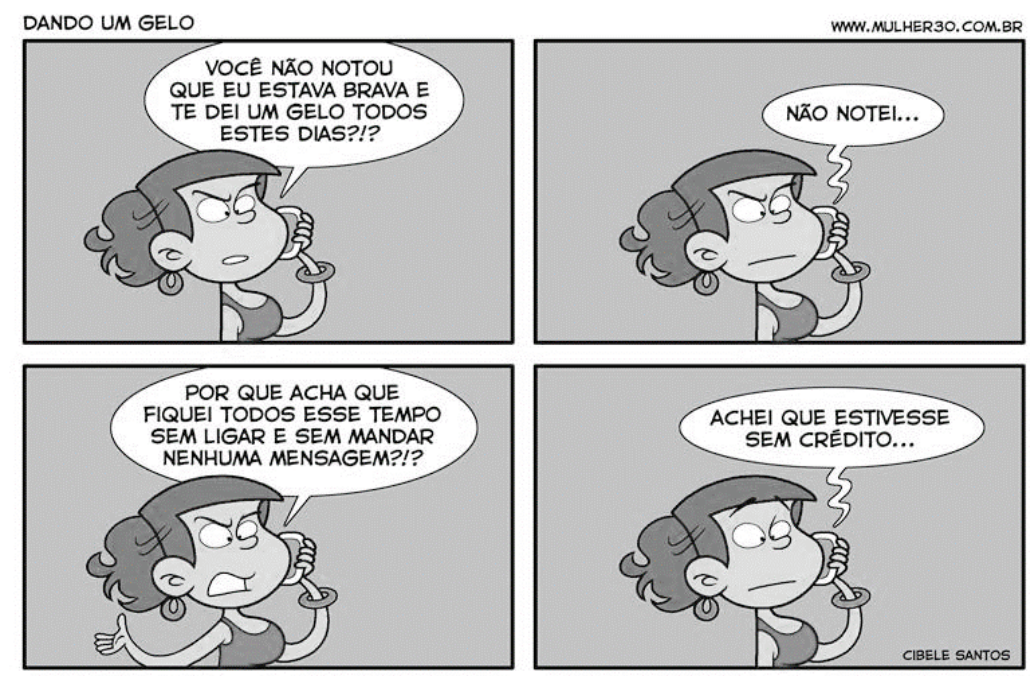

Fonte: Mulher de 30. Disponível em http://mulher30.com.br 
Nesta tirinha de Mulher de 30, Sabrina - intitulada como "a solteira" trata de um problema de comunicação em seu relacionamento. A personagem está incomodada com o fato de que um homem em sua vida não deu importância ao seu "silêncio". Na descrição que a autora faz da personagem, Sabrina aparece como uma mulher que está sempre atrás do Príncipe Encantado, mas só se envolve com os homens errados. Essa necessidade de estar envolvida com um homem poderia ser vista como a característica de "dependência do homem” que Courtney, Lockeretz (1971), Venkatesan e Losco (1975) retrataram. O cômico da situação se dá porque o tal homem com quem Sabrina se envolveu desta vez não percebeu o tratamento de silêncio, interpretando-o como uma falta de créditos no plano do celular da personagem feminina.

Figura 8 - Tira de “Mulher de 30" com a personagem Sabrina mais uma vez atrás do “homem ideal”

O CARA IDEAL

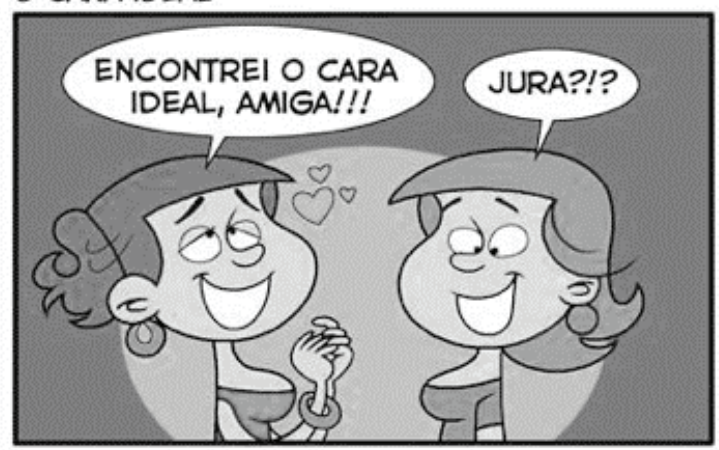

WWW.MULHER 30, COM.BR

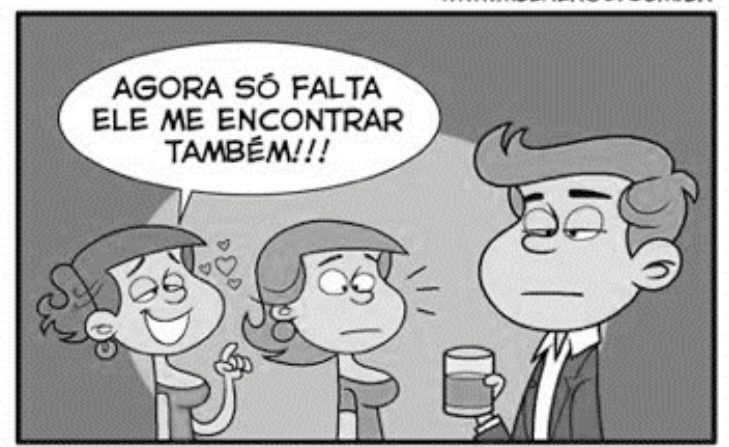

Fonte: Mulher de 30. Disponível em http://mulher30.com.br

Nesta tirinha, Sabrina aparece novamente numa cena em que busca pelo homem ideal, desta vez falando com uma amiga enquanto o personagem masculino existe à revelia de qualquer interação com a moça. Durante toda a obra Sabrina é definida pela sua busca de um homem que
Ihe complete. Esta é outra evidência de que a personagem se enquadra na categoria "dependente do homem", assinalada por Courtney, Lockeretz (1971) e Venkatesan e Losco (1975), ou seja, Sabrina precisa de um homem para definir sua existência como mulher.

Figura 9 - Tira de "Mulher de 30" com a personagem Vivi apresentando características de "boa vida"

\section{TUDO O QUE UMA BOLSA DEVE SER!}

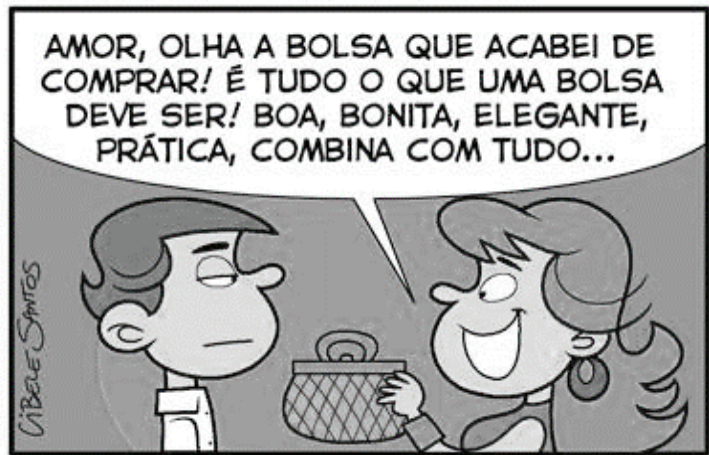

WWW.MULHER 30, COM.BR

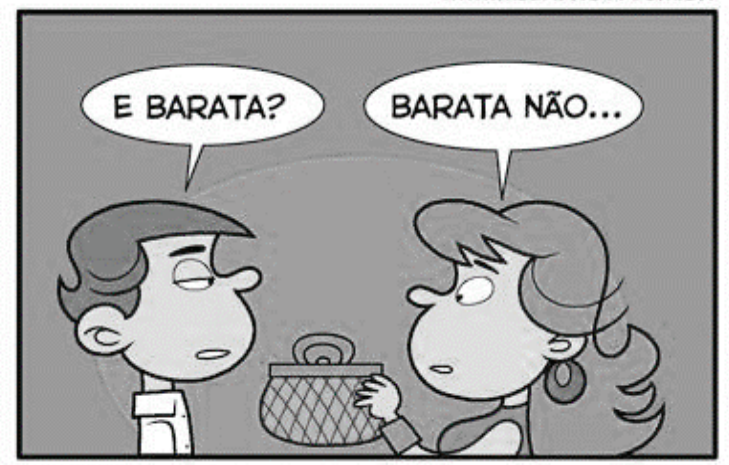

Fonte: Mulher de 30. Disponível em http://mulher30.com.br 
A terceira das tirinhas analisadas da série Mulher de 30 traz uma conversa entre a personagem Vivi e o personagem de seu marido. A mulher na tirinha de quadrinho está falando empolgada sobre a bolsa nova que comprou, enquanto o cônjuge ouve, pensando sobre o quanto o acessório custou, o que seria o fator cômico da situação. Vivi é a consumista compulsiva, diferentemente do seu marido, que é descrito como alguém "super pão-duro" e que "sofre para pôr a mulher na linha”. Vivi se encaixa na categoria de "boa vida" que aparece entre as classificações de representação da mulher de Venkatesan e Losco (1975). Os autores também associam a "boa vida" a consumidoras compulsivas, cujo foco é gastar dinheiro em atividades luxuosas.

\section{DISCUSSÃO}

Apesar do caráter indutivo do método e do tamanho da amostra, os resultados encontrados corroboram com as pesquisas já feitas por Acevedo, Arruda e Nohara (2005), bem como por Venkatesan e Losco (1975), Belkaoui (1976).

Nas tirinhas analisadas verifica-se que a mulher, quando retratada sob aspectos comportamentais considerados positivos pela sociedade, como "independência”, "super-mulher" ou "prodígio", tem esses perfis reformulados e apresentados ao leitor de modo caricatural. Isto ocorre porque tais posturas não se adequam à visão histórica de subserviência e submissão da mulher. Quando a mulher não é representada de forma positiva, utiliza-se da inserção de estereótipos, como no caso da mãe de Mafalda, em que as contradições de uma personagem que abandonou uma vida promissora pela lida doméstica geram uma comicidade amarga (DANTAS, 2006).

Os resultados obtidos neste estudo coadunam com os achados dos estudos de Moraes (2008) e Acevedo, Arruda e Nohara (2005) que também constataram em suas investigações categorias que são contraditórias entre si, como "independência", "postura submissa" e "dependente do homem", o que claramente revela um papel feminino incerto e coberto de contradições. Já em comparação com a pesquisa de Acevedo, Arruda e Nohara (2005), há pequenas divergências entre os resultados.

Naquele estudo, as autoras constataram $41,3 \%$ de frequência da categoria "fisicamente perfeita", 29,3\% da categoria "dependente" e $24 \%$ da "ritualização de subordinação" no período de análise de 1973 a 1980. Ressaltamos, porém a necessidade da utilização de categorias diferentes entre os dois estudos, pois as representações em peças publicitárias diferem daquelas utilizadas em tirinhas que têm o humor como o objetivo principal.

Além disso, foi evidenciado por diversos pesquisadores, tais como Venkatesan e Losco (1975), Belkaoui e Belkaoui (1976) e Acevedo, Arruda e Nohara (2005), que o retrato "dona de casa" é bastante recorrente na mídia. 0 principal exemplo encontrado no trabalho foi a personagem da mãe da Mafalda, que tem seu estereótipo invertido nos namorados de Aline. A hierarquia de poder em relação à mulher reflete-se na categoria feminina que Goffman (1978) e Kang (1997) descrevem como "postura submissa" onde, grosso modo, é o homem quem decide o que deve ser feito. No presente trabalho o pai de Aline vai definir se é aceitável ou não a sua relação com os dois rapazes, por exemplo.

Além disso, segundo Courtney e Lockeretz, (1971) e Venkatesan e Losco (1975), a figura do feminino é descrita como dependente do homem e que necessita de proteção masculina. Aline é tipificada por tratar com naturalidade temas "tabu", como sexo, consumo de drogas, poligamia etc. Como o humor da tira é baseado na inversão dos papéis estereotipados, ao criar uma personagem feminina que trabalha, sustenta dois namorados e tem total liberdade sexual, ressalta-se o papel inverso que é a dependência.

Assim, podemos ver nas tiras de Aline os estigmas do toque feminino (COURTNEY; LOCKERETZ, 1971) (culturalmente, espera-se que numa casa com mulher, as coisas sejam mais arrumadas que na de Aline), o de que lugar de mulher é em casa (COURTNEY; LOCKERETZ, 1971), o de objeto sexual (Aline é, afinal, uma ninfomaníaca). Por Kang (1997), também podemos apontar o estigma de exibição do corpo feminino, já que Aline se encontra nua em boa parte das tiras. 
Nas tiras da Mafalda, a personagem coadjuvante da mãe de Mafalda, também traz a nota o tópico de submissão, uma vez que é apresentada como uma mulher passiva. Esse posicionamento é alvo de críticas da personagem principal, que se recusa a aceitar que a mãe se sujeite a um papel de vassalagem. Mafalda é uma protagonista distante dos estigmas mais comuns das personagens femininas. Ela é qualificada como "criança prodígio" que carrega uma visão crítica do mundo muito além de sua experiência de vida.

0 tratamento dado por Quino aos personagens adultos também mostra uma certa condescendência do autor em relação ao público. Nas tiras analisadas, somente as crianças podem ser levadas a sério.

Apesar de nas tiras de Aline haver um flerte com a inversão dos papéis, podemos afirmar que esse enredo discute a independência da mulher. Por sua vez, Mafalda também aborda a questão da independência, bem como a sagacidade e o engajamento político, qualidades que são encarnadas pela protagonista da trama.

É importante notar que três décadas se passaram entre as publicações de "Mafalda" e "Aline”. A criação de Quino veio ao mundo durante o período militar argentino, enquanto a de Iturrusgarai nasceu no Brasil democrático dos anos 1990. As sociedades representadas nas tiras estão distantes de si na questão cronológica, mas o humor se mantém o mesmo. Tanto nos anos 1960 como nos 1990, os cartunistas se valeram da quebra de estereótipos para criticar comportamentos que eles observavam na sociedade de seu tempo, em ambos os casos, mostrou-se o papel que aquela sociedade esperava da mulher.

Por sua vez, na série Mulher de 30, a categoria "dependente do homem" é retratada mais frequentemente, tendo em vista que, os enredos das tiras narram preocupações das personagens em arranjar um relacionamento com um homem ideal. Outra categoria bastante recorrente é a "fisicamente bonita", que se utiliza do discurso disseminado socialmente de que a mulher deve estar em busca do corpo perfeito. Dessa forma, Mulher de 30 salienta o que a mídia representa como eternas preocupações da mulher, ou seja, a trindade: beleza física, relacionamento ideal e consumo.

\section{CONCLUSÃO}

A amostra utilizada produziu resultados que corroboram com os resultados anteriores de Acevedo, Arruda e Nohara (2005), entre outros autores. Segundo o que foi observado nestas tirinhas, quando as personagens femininas na mídia de massa são apresentadas de forma positiva (como independente, inteligente e atinada com assuntos políticos), elas estão ressaltando, ao mesmo tempo, comportamentos opostos. 0 humor gerado por uma personagem que se destaca por ser independente vem de uma inversão de expectativa que dita que a norma é ser o oposto de seu comportamento. Desta forma, por mais que Aline quebre estereótipos com sua postura progressista e Mafalda com sua visão de mundo adulta, acabam por reforçar na sociedade as representações daquilo que estas personagens não são.

Já em relação à tira Mulher de 30 , não existe nem o que se poderia chamar de uma inversão do estereótipo. Todo o humor encontrado nestes quadrinhos é advindo da familiaridade com os estereótipos compartilhados entre autora e público.

\section{REFERÊNCIAS}

\section{ACEVEDO, Claudia Rosa. Perfil do comportamento dos consumidores maduros em viagens de lazer. 1998. 250f. Tese (Doutorado) - Pós-graduação da EAESP/FGV, Área de concentração: mercadologia, EAESP/FGV, São Paulo, 1998.}

ACEVEDO, C.R.; ARRUDA, A.L.; NOHARA, J.J. A content analysis of the roles portrayed by women in television advertisements: 1973-2000. Encontro

Nacional da ANPAD, 29, Brasília, v.1, 2005.

\section{BARCELLOS, Janice Primo. Histórias em}

quadrinhos, comunicação e informação. São Paulo: Escola de Comunicações e Artes da Universidade de São Paulo, 1999.

BARDIN, L. Análise de conteúdo. 70.ed. Lisboa, 1977. 
BELKAOUI, A.; BELKAOUI, J.M. A comparative analysis of the roles portrayed by women in print advertisements: 1958, 1970, 1972. Journal of Marketing Research, XIII, p.168-172, maiyo 1976.

CAIXETA, S. P. Anos dourados: a mulher-maravilha e o papel da mulher norte-americana durante a $2^{\mathrm{a}}$ Guerra Mundial. Temática, v.8, n.4, 2015.

COURTNEY, A.E.; LOCKERETZ, S.W. A Woman's Place: an Analysis of The Roles Portrayed by Women in Magazine Advertisements. Journal of Marketing Research, v.8, p.92-95, fev. 1971

DANTAS, Dayani Ferreira. Sexo, mentiras e HQ: representação e auto-representação das mulheres nos quadrinhos. Recife: Universidade Federal de Pernambuco, março de 2006.

EISNER, Will. Quadrinhos e arte aeqüencial. São Paulo: Martins Fontes, 1989.

GOFFMAN, E. Gender Advertisements. Cambridge, MA: Harvard University Press, 1978

ITURRUSGARAI, A. Aline: era uma vez... São Paulo: Devir, 2001.

JAFFE, L.; BERGER, P. The Effect of Modern Female Sex Role Portrayals on Advertising Effectiveness. Journal of Advertising Research, p.32-43, jul-aug. 1994.
KANG, M. The portrayal of women's images in magazine advertisements: Goffman's gender analysis revisited. Sex Roles, v.37, n.11, p.979-996, 1997.

LAVIN, Michael R. Women in Comic Books. Serials Review, v.24, 2.ed, 1998.

MATTAR, F. Pesquisa de marketing. São Paulo: Atlas, 1994. p.350.

MAZZARA, Bruno M. Estereótipos y prejuicios. Madrid: Acento, 1999.

QUINO. Mafalda inédita. São Paulo: Martins Fontes, 1993.

SABAT, R. Pedagogia cultural, gênero e sexualidade. Estudos Feministas, 11 (2º Semester, Year 9), 2001.

SANTOS, Cibele. Mulher de 30. Disponível em: <http://mulher30.com.br>. Acesso em: 4 dez. 2014.

VENKATESAN, M.; LOSCO, J.P. Women in magazine ads: 1959-71. Journal of Advertising Research, v.15, p.49-54, oct. 5, 1975.

1 Doutora em Administração de Empresas pela - FGV-SP; Graduada em Economia - USP. E-mail: claudiaraac@gmail.com

2 Pesquisador; Bacharel em Marketing.

E-mail: Bruno.catao@gmail.com

3 Pesquisadora; Bacharela em Marketing.

E-mail: carol_rali@hotmail.com

4 Pós-Doutoranda em Administração - FEARP-USP; Doutora em Administração - FEA-USP; Graduada em Ciências Econômicas pelo Centro Universitário Moura Lacerda (1999); Mestrado em Administração pelo Centro Universitário de Franca (2005).

E-mail: hrstamashiro@ibest.com.br 